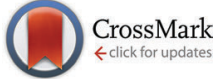

Cite this: Chem. Commun., 2015, 51,8773

Received 10th March 2015, Accepted 16th April 2015

DOI: $10.1039 / c 5 c c 02023 a$

www.rsc.org/chemcomm

\title{
Synthesis of chiral cyclobutanes via rhodium/ diene-catalyzed asymmetric 1,4-addition: a dramatic ligand effect on the diastereoselectivity $\dagger$
}

\author{
Ya-Jing Chen, Tian-Jiao Hu, Chen-Guo Feng* and Guo-Qiang Lin
}

\begin{abstract}
A highly diastereo- and enantioselective rhodium-catalyzed arylation of cyclobutenes for the efficient synthesis of chiral cyclobutanes has been developed. Chiral diene ligands exhibited excellent capability for the reaction diastereoselectivity control.
\end{abstract}

Chiral cyclobutanes exist as core subunits in numerous natural products $^{1,2}$ and pharmaceutical agents. ${ }^{3}$ Moreover, a number of interesting chemical transformations associated with the fourmembered strained ring render them valuable building blocks for organic synthesis. ${ }^{4}$ As a result, significant efforts have been directed to the asymmetric construction of chiral cyclobutane rings, ${ }^{5}$ and some catalytic asymmetric methods have been developed during the past decades, including asymmetric organo- $^{6}$ or Lewis acid-catalyzed [2+2] cycloaddition, ${ }^{7}$ asymmetric ring expansion of cyclopropanes, ${ }^{8}$ asymmetric intramolecular ring closure of linear substrates ${ }^{9}$ and asymmetric functionalization of prochiral cyclobutane derivatives. ${ }^{10-12}$ The last strategy can avoid the relatively difficult construction of the constrained ring. More importantly, it provides a diverse synthetic approach using different functionalization reactions and easily accessible cyclobutanes as starting materials. To the best of our knowledge, almost all the present successful examples are limited to the chemical modifications of cyclobutanone substrates (Scheme 1, eqn (1)). ${ }^{10}$ Very recently, Yu and coworkers reported the asymmetric $\mathrm{C}-\mathrm{H}$ activation/arylation of cyclobutane rings (eqn (2)). ${ }^{11}$ Maulide and co-workers reported the palladium-catalyzed allylic alkylation of 4-chlorocyclobut2-enecarboxylic acid (eqn (3)). ${ }^{12}$ We envisioned that the wellestablished asymmetric rhodium-catalyzed addition of organometallic reagents to electron deficient double bonds could lead to a straightforward and diverse access to chiral cyclobutanes. ${ }^{13}$ Although five- and six-membered counterparts are among the

CAS Key Laboratory of Synthetic Chemistry of Natural Substances, Shanghai Institute of Organic Chemistry, Chinese Academy of Sciences,

Shanghai 200032, P. R. China. E-mail: fengcg@sioc.ac.cn; Fax: +86 215080 7388; Tel: +862154925081

$\dagger$ Electronic supplementary information (ESI) available. CCDC 1042990. For ESI and crystallographic data in CIF or other electronic format see DOI: 10.1039/c5cc02023a
- Asymmetric functionalization with cyclobutanone substrates
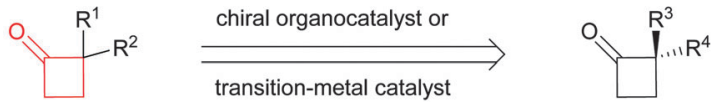

- Enantioselective arylation of cyclobutanecarboxylic amide

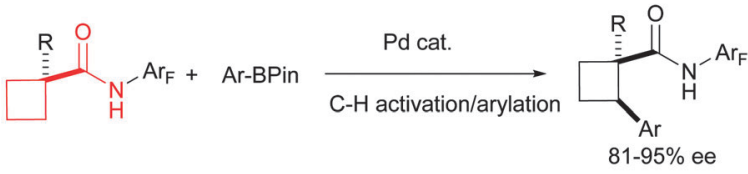

- Enantioselective allylic alkylation of cyclobutanecarboxylic acid

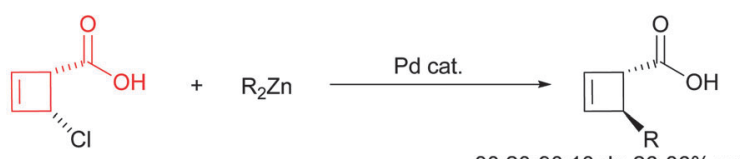

$80: 20-90: 10$ dr, $26-86 \%$ ee

- This work: rhodium-catalyzed arylation of cyclobutene substrates

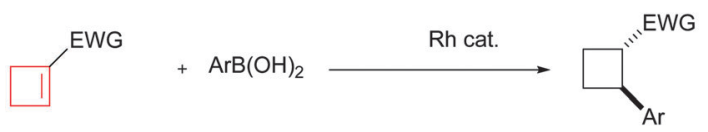

- Easily accessible starting material

- High enantioselectivity and diastereoselectivity

Scheme 1 Asymmetric functionalization of cyclobutane derivatives.

most tested substrates in rhodium-catalyzed 1,4-additions, only a single non-asymmetric example of the addition to cyclobutene was introduced by Tang and co-workers ${ }^{14}$ in their synthesis toward pipercyclobutanamide $\mathrm{A}$ and piperchabamide $\mathrm{G}$ and its asymmetric version remains unreported.

We reason that cyclobutene-1-carboxylate esters are suitable precursors for the enantioselective synthesis of chiral cyclobutanes, which can be easily prepared via three steps from widely available ethyl cyclobutanecarboxylate ${ }^{15}$ and the ester groups could serve as a handle for further functionalization. However, it would be challenging to control both stereogenic centers generated in the addition process with such substrates. Especially, upon the first enantioselective addition at the $\beta$-position, 
Table 1 Rhodium-catalyzed 1,4-addition of phenylboronic acid to cyclobutene-1-carboxylates: effect of ester groups ${ }^{a}$

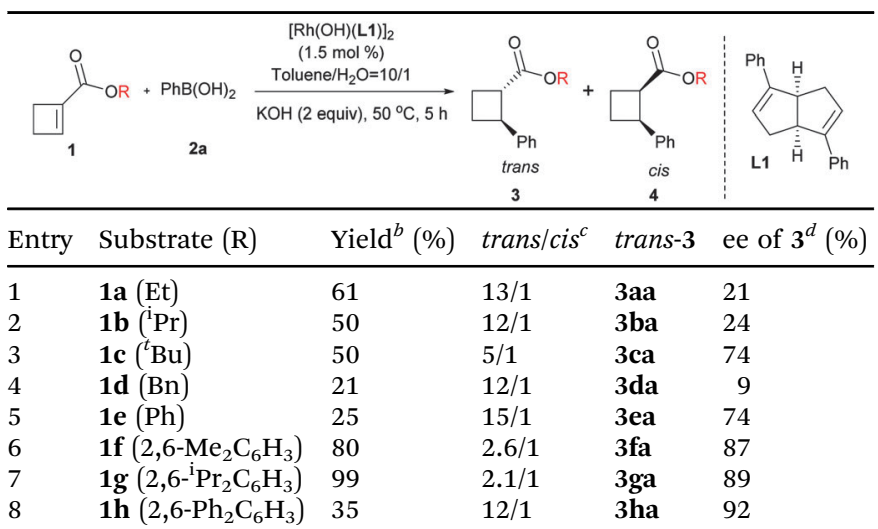

${ }^{a}$ Reactions were carried out with 1 (0.1 mmol), 2a $(0.2 \mathrm{mmol})$, $[\mathrm{Rh}(\mathrm{OH})(\mathbf{L 1})]_{2}(0.0015 \mathrm{mmol}), 2.0 \mathrm{M}$ aq. $\mathrm{KOH}(0.2 \mathrm{mmol})$ in toluene $(1 \mathrm{~mL})$ at $50{ }^{\circ} \mathrm{C}$ for 5 h. ${ }^{b}$ A combined isolated yield of 3 and 4 . ${ }^{c}$ Determined by GC analysis. ${ }^{d}$ Determined by chiral HPLC analysis.

the subsequent protonation of the resulting oxa- $\pi$-allylrhodium intermediate would generate a second chiral center, which is usually quite difficult to control unless the $\alpha$-substituent can induce a different protonation pathway in the reported similar examples. ${ }^{16}$ Herein, we report our research on the ligand enabled highly diastereo- and enantioselective rhodiumcatalyzed arylation of cyclobutene-1-carboxylate esters for the efficient synthesis of chiral cyclobutanes.

First, we tested the addition of phenylboronic acid to the ethyl ester substrate (1a) in the presence of the active hydroxo rhodium complex $[\mathrm{Rh}(\mathrm{OH})(\mathbf{L 1})]{ }^{17}$ Gratifyingly, the reaction took place smoothly, affording the desired product in $61 \%$ yield with high diastereoselectivity despite low enantioselectivity. It was reported that the ester substituents could affect the stereoselectivity control for the aryl addition to linear $\alpha, \beta$-unsaturated ester systems, ${ }^{18}$ thus a variety of different esters were examined in our case (Table 1). Although more sterically hindered substituents clearly improved the enantioselectivity, the reaction yield and diastereoselectivity were highly dependent on the structure pattern of substituents. The 2,6-diphenylphenyl substituent provided the highest enantioselectivity and maintained high diastereoselectivity, but a reduced reaction yield (entry 8).

Next, we turned to investigate this reaction using an in situ generated chiral rhodium catalyst. With ester $\mathbf{1 h}$ as a substrate and $\left[\mathrm{RhCl}\left(\mathrm{C}_{2} \mathrm{H}_{4}\right)_{2}\right]_{2}$ as a precatalyst, a variety of chiral ligands were examined (Table 2). ${ }^{19}$ A significantly improved yield was obtained from the same ligand $\mathbf{L 1}$ (entry 1 vs. Table 1, entry 8). However, attempts to further increase the enantioselectivity of this reaction by introducing different substituents to the phenyl ring of ligand $\mathbf{L} 1$ were unsuccessful. It is worth mentioning that the diastereoselectivity was significantly improved by the introduction of electron-withdrawing substituents (entries 2-9). The highest diastereoselectivity was achieved using para $4-\mathrm{CF}_{3} \mathrm{O}$ substituted ligand $\mathbf{L 8}$, albeit with a slight loss in reaction yield, which was brought back by a lower temperature and a prolonged reaction time (entries 8 and 9). Bicyclo[2.2.2]octadiene $\mathbf{L 9}^{20}$ gave a similar reaction yield and diastereoselectivity
Table 2 Rhodium-catalyzed 1,4-addition of phenylboronic acid to cyclobutene-1-carboxylate $\mathbf{1 h}$ : the effect of chiral ligands ${ }^{a}$

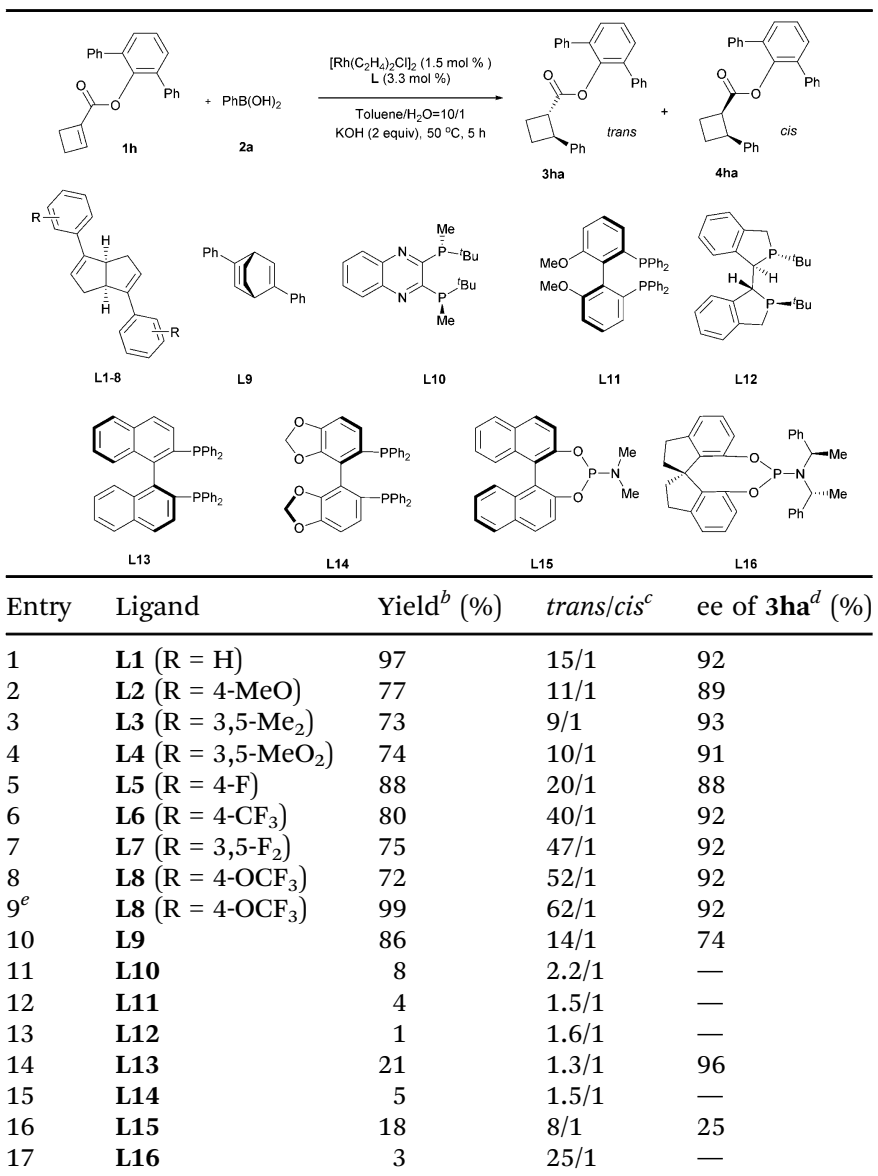

${ }^{a}$ Reactions were carried out with $\mathbf{1 h}(0.1 \mathrm{mmol}), 2 \mathrm{2a}(0.2 \mathrm{mmol})$, $\left[\mathrm{Rh}\left(\mathrm{C}_{2} \mathrm{H}_{4}\right)_{2} \mathrm{Cl}\right]_{2}(0.0015 \mathrm{mmol}), \mathbf{L}(0.0033 \mathrm{mmol}), 2.0 \mathrm{M}$ aq. $\mathrm{KOH}$ $(0.2 \mathrm{mmol})$ in toluene $(1 \mathrm{~mL})$ at $50{ }^{\circ} \mathrm{C}$ for $5 \mathrm{~h}$ unless otherwise noted. ${ }^{b}$ A combined yield of 3 ha and 4 ha, which was determined by GC using dodecane as an internal standard. ${ }^{c}$ Determined by GC. ${ }^{d}$ Determined by chiral HPLC analysis. ${ }^{e}$ Reaction was made to run at $30{ }^{\circ} \mathrm{C}$ for $24 \mathrm{~h}$.

compared with L1, but with lower enantioselectivity (entry 10). All the tested phosphine-containing ligands failed to promote this reaction effectively and only a trace amount of the product was generated in most cases under current reaction conditions (entries 11-17). Interestingly, while bisphosphine ligands gave low diastereoselectivities, relatively electron-deficient phosphoramidite ligands showed much higher diastereoselectivities, consistent with the trend observed for diene ligands. The high diastereoselectivity control by electron-deficient ligands may be attributed to the quick protonation of the carbon-rhodium bond, which was generated after the cis addition of the aryl rhodium species to the olefin. The stereochemically retentive direct protonation step could prevent the uncontrollable oxa- $\pi$-allylrhodium protonation pathway, ${ }^{21}$ thus the addition reaction led to the trans product.

With optimal reaction conditions identified (Table 2, entry 9), a wide range of arylboronic acids were explored as depicted in Table 3. Excellent diastereoselectivities were obtained for all the tested arylboronic acids although the reaction yields were affected by both steric and electronic properties of aryl groups. 
Table 3 Rhodium-catalyzed 1,4-addition of arylboronic acid to cyclobutene-1-carboxylate $1 \mathbf{h}^{a}$

\begin{tabular}{|c|c|c|c|c|c|}
\hline \multirow{2}{*}{$\frac{\text { Lntry }}{\text { Ent }}$} & \multirow{2}{*}{$\frac{1 \mathrm{~h}}{\mathrm{Ar}}$} & \multicolumn{2}{|c|}{$\begin{array}{c}{\left[\begin{array}{c}{\left[\mathrm{Rh}\left(\mathrm{C}_{2} \mathrm{H}_{4}\right)_{2} \mathrm{Cl}\right]_{2}(1.5 \mathrm{~mol} \%)} \\
\mathrm{L8}(3.3 \mathrm{~mol} \%)\end{array}\right.} \\
\text { Toluene } / \mathrm{H}_{2} \mathrm{O}=10 / 1 \\
\mathrm{KOH}\left(2 \text { equiv), } 30 \text { or } 50^{\circ} \mathrm{C}, 24 \mathrm{~h}\right.\end{array}$} & \multirow{2}{*}{\multicolumn{2}{|c|}{$\frac{\stackrel{\text { trans }}{3}}{\mathrm{ee}^{d}(\%)}$}} \\
\hline & & trans-3 & Yield $^{b}(\%)$ & & \\
\hline 1 & $\mathrm{Ph}(\mathbf{2 a})$ & 3ha & 99 & $62 / 1$ & 92 \\
\hline 2 & $4-\mathrm{MeOC}_{6} \mathrm{H}_{4}(2 \mathbf{b})$ & $3 \mathbf{h b}$ & 90 & $99 / 1$ & 89 \\
\hline 3 & $4{ }^{t}{ }^{t} \mathrm{BuC}_{6} \mathrm{H}_{4}(2 \mathrm{c})$ & 3he & 97 & $49 / 1$ & 93 \\
\hline 4 & $4-\mathrm{CF}_{3} \mathrm{C}_{6} \mathrm{H}_{4}(2 \mathrm{~d})$ & 3hd & 73 & $32 / 1$ & 98 \\
\hline $5^{e}$ & $4-\mathrm{CO}_{2} \mathrm{MeC}_{6} \mathrm{H}_{4}(\mathbf{2 e})$ & 3he & 36 & $>99 / 1$ & 92 \\
\hline 6 & $4-\mathrm{FC}_{6} \mathrm{H}_{4}(\mathbf{2 f})$ & $3 \mathrm{hf}$ & 78 & $32 / 1$ & 97 \\
\hline 7 & $4-\mathrm{ClC}_{6} \mathrm{H}_{4}(2 \mathrm{~g})$ & $3 h g$ & 96 & $49 / 1$ & 97 \\
\hline 8 & $4-\mathrm{BrC}_{6} \mathrm{H}_{4}(\mathbf{2 h})$ & $3 \mathrm{hh}$ & 92 & $49 / 1$ & 96 \\
\hline 9 & $3-\mathrm{MeOC}_{6} \mathrm{H}_{4}(\mathbf{2 i})$ & $3 \mathrm{hi}$ & 91 & $>99 / 1$ & 93 \\
\hline 10 & $3-\mathrm{FC}_{6} \mathrm{H}_{4}(2 \mathbf{j})$ & $3 \mathbf{h j}$ & 84 & $49 / 1$ & 97 \\
\hline 11 & $3-\mathrm{CO}_{2} \mathrm{MeC}_{6} \mathrm{H}_{4}(\mathbf{2 k})$ & $3 \mathrm{hk}$ & 95 & $32 / 1$ & 96 \\
\hline $12^{e}$ & 2-MeO (2l) & $3 \mathrm{hl}$ & 51 & $16 / 1$ & 96 \\
\hline 13 & 1-Naphthyl (2m) & $3 \mathrm{hm}$ & 96 & $>99 / 1$ & 83 \\
\hline 14 & 2-Naphthyl (2n) & $3 \mathrm{hn}$ & 68 & $>99 / 1$ & 87 \\
\hline
\end{tabular}

${ }^{a}$ Reactions were carried out with $1 \mathrm{~h}(0.2 \mathrm{mmol}), 2$ (0.4 mmol), $\left[\mathrm{Rh}\left(\mathrm{C}_{2} \mathrm{H}_{4}\right)_{2} \mathrm{Cl}\right]_{2}(0.003 \mathrm{mmol}), \mathbf{L 8}(0.0066 \mathrm{mmol}), 2.0 \mathrm{M}$ aq. KOH $(0.4 \mathrm{mmol})$ in toluene $(2 \mathrm{~mL})$ at $30{ }^{\circ} \mathrm{C}$ for $24 \mathrm{~h}$ unless otherwise noted. ${ }^{b}$ Isolated yield. ${ }^{c}$ Determined by GC. ${ }^{d}$ Determined by chiral HPLC analysis. ${ }^{e} 50{ }^{\circ} \mathrm{C}$.

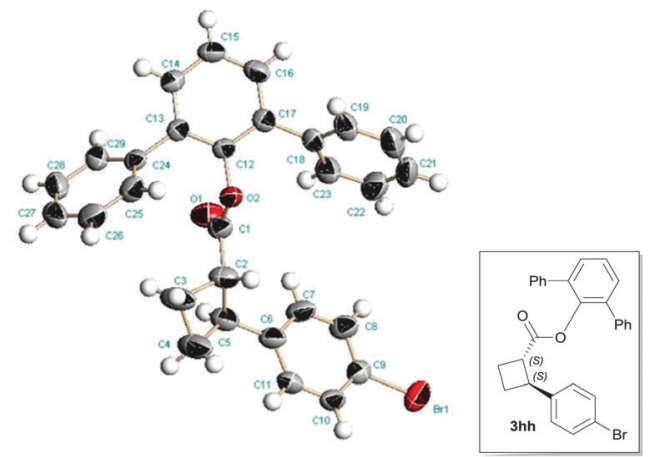

Scheme 2 The $\mathrm{X}$-ray diffraction structure of $3 \mathrm{hh}$

In general, electron-donating groups at the para position of the phenyl ring would benefit the reaction yields, and the sterically hindered ortho-substituted arylboronic acid gave only moderate reaction yield even at elevated reaction temperature. As for the enantioselectivity, the reactions with most arylboronic acids provided good to excellent ees (83-98\%). The absolute configuration of product $3 \mathbf{h h}$ was ambiguously determined by a singlecrystal X-ray analysis as depicted in Scheme $2,{ }^{22}$ and other products were assigned by analogy.

The obtained products can be easily converted to other cyclobutane derivatives. As shown in Scheme 3, reduction of ester 3ha with $\mathrm{LiAlH}_{4}$ at room temperature furnished alcohol 5 in $97 \%$ yield. The hydrolysis could provide acid 6 in $89 \%$ yield. Treatment of ester 3ha with lithium diisopropylamide (LDA) followed by alkylation with allyl iodide afforded product 7 as a single diastereomer with a negligible loss in optical purity.

In summary, we have developed a highly diastereo- and enantioselective rhodium-catalyzed arylation of cyclobutene-1-carboxylate

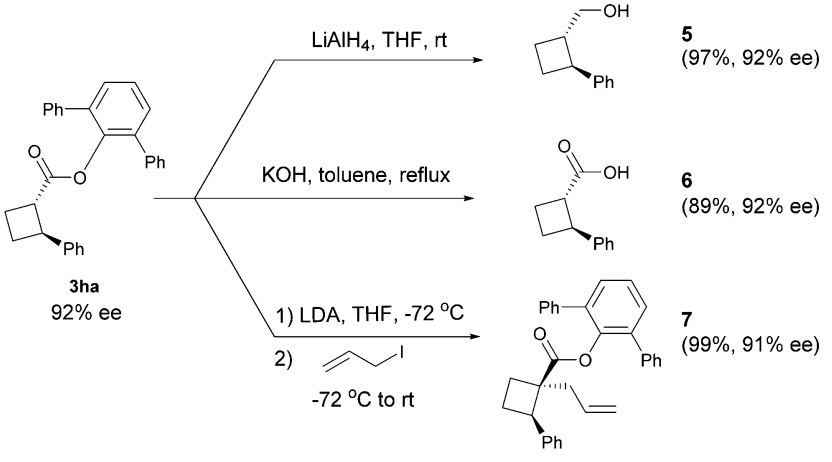

Scheme 3 Transformations of product 3 ha.

esters, which provides an efficient synthetic approach for chiral butanes. Chiral diene ligands, especially electron deficient ones, exhibited excellent diastereoselectivity control. In addition, the versatile transformations of the product warrant the synthetic utility of this methodology.

This work was generously supported by the National Natural Science Foundation of China (21472212), the Shanghai Municipal Committee of Science and Technology (14ZR1448500) and the Collaborative Innovation Center of Chemical Science and Engineering (Tianjing). We acknowledge Dr Han-Qing Dong for his help in the preparation of this manuscript.

\section{Notes and references}

1 For review: V. M. Dembitsky, J. Nat. Med., 2008, 62, 1-33.

2 For selected examples: (a) P. S. Baran, D. P. O'Malley and A. L. Zografos, Angew. Chem., Int. Ed., 2004, 43, 2674-2677; (b) H. Ito, M. Hasegawa, Y. Takenaka, T. Kobayashi and K. Iguchi, J. Am. Chem. Soc., 2004, 126, 4520-4521; (c) K. Takao, N. Hayakawa, R. Yamada, T. Yamaguchi, H. Saegusa, M. Uchida, S. Samejima and K. Tadano, J. Org. Chem., 2009, 74, 6452-6461.

3 For selected examples: (a) J. Singh, G. S. Bisacchi, S. Ahmad, J. D. Godfrey, Jr., T. P. Kissick, T. Mitt, O. Kocy, T. Vu, C. G. Papaioannou, M. K. Wong, J. E. Heikes, R. Zahler and R. H. Mueller, Org. Process Res. Dev., 1998, 2, 393-399; (b) P. Maity and B. König, Biopolymers, 2008, 90, 8-27.

4 For review: (a) J. C. Namyslo and D. E. Kaufmann, Chem. Rev., 2003, 103, 1485-1537; (b) T. Seiser, T. Saget, D. N. Tran and N. Cramer, Angew. Chem., Int. Ed., 2011, 50, 7740-7752.

5 For review: E. Lee-Ruff and G. Mladenova, Chem. Rev., 2003, 103, 1449-1483.

6 (a) K. Ishihara and K. Nakano, J. Am. Chem. Soc., 2007, 129, 8930-8931; (b) G. Talavera, E. Reyes, J. L. Vicario and L. Carrillo, Angew. Chem., Int. Ed., 2012, 51, 4104-4107; (c) G.-J. Duan, J.-B. Ling, W.-P. Wang, Y.-C. Luo and P.-F. Xu, Chem. Commun., 2013, 49, $4625-4627$.

7 (a) T. A. Engler, M. A. Letavic, R. Iyengar, K. O. LaTessa and J. P. Reddy, J. Org. Chem., 1999, 64, 2391-2405; (b) E. Canales and E. J. Corey, J. Am. Chem. Soc., 2007, 129, 12686-12687; (c) S. SuárezPantiga, C. Hernández-Díaz, E. Rubio and J. M. Gonzalez, Angew. Chem., Int. Ed., 2012, 51, 11552-11555.

8 F. Kleinbeck and F. D. Toste, J. Am. Chem. Soc., 2009, 131, 9178-9179.

9 (a) R. Panish, S. R. Chintala, D. T. Boruta, Y. Z. Fang, M. T. Taylor and J. M. Fox, J. Am. Chem. Soc., 2013, 135, 9283-9286; (b) Y. X. Liu, Y. Liu, C. S. Shanahan, X. Xu and M. P. Doyle, Org. Biomol. Chem., 2014, 12, 5227-5234.

10 (a) M. Lopp, A. Paju, T. Kanger and T. Pehk, Tetrahedron Lett., 1996, 37, 7583-7586; (b) D. Hazelard and A. Fadel, Tetrahedron: Asymmetry, 2005, 16, 2067-2070; (c) D. Mailhol, M. M. Sanchez Duque, W. Raimondi, D. Bonne, T. Constantieux, Y. Coquerel and J. Rodriguez, Adv. Synth. Catal., 2012, 354, 3523-3532; 
(d) D. J. Aitken, P. Caboni, H. Eijsberg, A. Frongia, R. Guillot, J. Ollivier, P. P. Piras and F. Secci, Adv. Synth. Catal., 2014, 356, 941-945; (e) C. M. Reeves, C. Eidamshaus, J. Kim and B. M. Stoltz, Angew. Chem., Int. Ed., 2013, 52, 6718-6721.

11 K.-J. Xiao, D. W. Lin, M. Miura, R.-Y. Zhu, W. Gong, M. Wasa and J.-Q. Yu, J. Am. Chem. Soc., 2014, 136, 8138-8142.

12 A. Misale, S. Niyomchon, M. Luparia and N. Maulide, Angew. Chem., Int. Ed., 2014, 53, 7068-7073.

13 For leading reviews on Rh-catalyzed asymmetric conjugated additions: (a) T. Hayashi and K. Yamasaki, Chem. Rev., 2003, 103, 2829-2844; (b) C. Gennari, C. Monti and U. Piarulli, Pure Appl. Chem., 2006, 78, 303-310; (c) J. Christoffers, G. Koripelly, A. Rosiak and M. Röessle, Synthesis, 2007, 1279-1300; (d) H. J. Edwards, J. D. Hargrave, S. D. Penrose and C. G. Frost, Chem. Soc. Rev., 2010, 39, 2093-2105.

14 R. Liu, M. Zhang, T. P. Wyche, G. N. Winston-McPherson, T. S. Bugni and W. Tang, Angew. Chem., Int. Ed., 2012, 51, 7503-7506.

15 (a) A. Campbell and H. N. Rydon, J. Chem. Soc., 1953, 3002-3008; (b) J. C. Lee, K. A. Parker and N. S. Sampson, J. Am. Chem. Soc., 2006, 128, 4578-4579; (c) M. E. Jung and G. Deng, J. Org. Chem., 2012, 77, 11002-11005.

16 (a) T. Hayashi, T. Senda and M. Ogasawara, J. Am. Chem. Soc., 2000, 122, 10716-10717; (b) L. Navarre, S. Darses and J.-P. Genet, Angew. Chem., Int. Ed., 2004, 43, 719-723; (c) R. J. Moss, K. J. Wadsworth, C. J. Chapman and C. G. Frost, Chem. Commun., 2004, 1984-1985; (d) L. Navarre, R. Martinez, J.-P. Genet and S. Darses, J. Am. Chem. Soc., 2008, 130, 6159-6169; (e) X. Zhang, G. Chen, P. Cao, J. Liu and J. Liao, Tetrahedron Lett., 2012, 53, 438-441.

17 (a) Z.-Q. Wang, C.-G. Feng, M.-H. Xu and G.-Q. Lin, J. Am. Chem. Soc., 2007, 129, 5336-5337; (b) S. Helbig, S. Sauer, N. Cramer, S. Laschat, A. Baro and W. Frey, Adv. Synth. Catal., 2007, 349, 2331-2337; (c) Z. Cui, H.-J. Yu, R.-F. Yang, W.-Y. Gao, C.-G. Feng and G.-Q. Lin, J. Am. Chem. Soc., 2011, 133, 12394-12397.

18 (a) J.-F. Paquin, C. R. J. Stephenson, C. Defieber and E. M. Carreira, Org. Lett., 2005, 7, 3821-3824; (b) T. Itoh, T. Mase, T. Nishikata, T. Iyama, H. Tachikawa, Y. Kobayashi, Y. Yamamoto and N. Miyaura, Tetrahedron, 2006, 62, 9610-9621; (c) R. Shintani and T. Hayashi, Org. Lett., 2011, 13, 350-352.

19 Reviews of chiral olefin ligands: (a) C. Defieber, H. Grüetzmacher and E. M. Carreira, Angew. Chem., Int. Ed., 2008, 47, 4482-4502; (b) J. B. Johnson and T. Rovis, Angew. Chem., Int. Ed., 2008, 47, 840-871; (c) R. Shintani and T. Hayashi, Aldrichimica Acta, 2009, 42, 31-38; (d) C.-G. Feng, M.-H. Xu and G.-Q. Lin, Synlett, 2011, 1345-1356; (e) X. Feng and H. Du, Asian J. Org. Chem., 2012, 1, 204-213.

20 N. Tokunaga, Y. Otomaru, K. Okamoto, K. Ueyama, R. Shintani and T. Hayashi, J. Am. Chem. Soc., 2004, 126, 13584-13585.

21 C. M. So, S. Kume and T. Hayashi, J. Am. Chem. Soc., 2013, 135, 10990-10993.

22 CCDC 1042990 contains the supplementary crystallographic data for compound $3 \mathbf{h h}$. 